\title{
Special issue on companion animal genetics: Novel variants discovered in wide variety of diseases in dogs, identification and further characterization of traits in dogs and cats, and the use of microarrays in the detection of aneuploidy in dogs
}

\author{
Lisa G. Shaffer ${ }^{1,2}$ \\ Published online: 1 October 2021 \\ ๑ The Author(s), under exclusive licence to Springer-Verlag GmbH Germany, part of Springer Nature 2021
}

Keywords Canine $\cdot$ Canine genetics $\cdot$ Feline $\cdot$ Feline genetics $\cdot$ Animal models $\cdot$ Inherited dog disease $\cdot$ Inherited cat traits . Genetic testing

\section{Introduction}

Companion animals hold special places in our hearts and homes. Dogs and cats not only provide companionship but can serve as important animal models for inherited human diseases and conditions. Since the previous special issue of Human Genetics on canine genetics (Shaffer 2019), about 100 additional variants have been identified in the domestic dog (OMIA: Online Mendelian Inheritance in Animals 2021 ), bringing the total to nearly 450 variants contributing to diseases and traits. Included for the first time in this special issue on companion animals is the domestic cat and nearly 150 variants have been identified that contribute to diseases and traits in our feline friends.

Domestication in both dogs and cats has led to the development of specific breeds characterized by desired traits in behavior and appearance. During selective breeding to produce the various breeds, recessive, and sometimes deleterious, alleles may have also been inadvertently selected leading to diseases associated with one or a few related dog breeds. Depending on when the mutation arose during breed development determines how many dog breeds might be at risk. In some instances, the desired trait may also be associated with adverse outcomes (Rorden et al. 2021) based

Lisa G. Shaffer

Lshaffer@pawprintgenetics.com

1 Paw Print Genetics, Genetic Veterinary Sciences, Inc., 220 E Rowan, suite 220, Spokane, WA 99207, USA

2 Center for Reproductive Biology, Washington State University, Pullman, WA, USA on dosage, incomplete penetrance, variable expressivity, or modifiers elsewhere in the genome.

This special issue of Human Genetics on companion animal genetics contains many exciting examples of the new discoveries happening in both canine and feline genomics.

\section{Databases provide helpful resources to pet owners, breeders, and veterinarians}

In addition to the OMIA database and the Orthopedic Foundation for Animals (OFA: Orthopedic Foundation for Animals 2021), the World Small Animal Veterinary Association and the University of Pennsylvania School of Veterinary Medicine clinical testing laboratory known as PennGen provide a database of available feline and canine tests and the laboratories that perform them. Rokhsar et al. (2021) provide an update on this DNA testing resource and compare the current compilation to their previous data review from 2012. This opening article to this special issue sets the stage for the novel discoveries that follow on this topic.

\section{New discoveries and understandings for inherited traits in cats and dogs}

In many cases, for both dogs and cats, the physical appearance of an animal immediately informs one of the breed. In this issue, cats with a dominant variant in TRPV4 that causes ear folding in the Scottish Fold were investigated in a blinded fashion for concomitant effects on bone and cartilage leading to osteochondrodysplasia and osteoarthritis 
(Rorden et al. 2021). High variability in extent of disease and progression was found among study subjects and even in some control cats; although, in general, cats with one copy of the variant could be distinguished from cats homozygous for the wild-type allele.

In the second feline study in this special issue, Shaffer et al. (2021a) identified a fifth variant in FGF5 and this variant is responsible for longhair in some Maine coon cats. Longhair in both cats and dogs is caused by recessive mutations in $F G F 5$. DNA sequencing of only two animals that were longhaired but showed only one known $F G F 5$ variant revealed that the cats were compound heterozygotes for an additional, novel variant. Screening 345 additional cats identified a total of four Maine coons with this variant, but no other breeds. Thus, the identification of this novel variant is an excellent example of allelic heterogeneity and further demonstrates that certain variants may be identified in only one or a few related breeds.

Speaking of allelic heterogeneity, the merle coat pattern in dogs (also known as dapple in the dachshund) is caused by variable sized insertions of a SINE into PMEL. Ballif et al. (2018) and others have characterized the sizes of the insertions and correlated those with coat patterns. In this special issue, Ballif et al. (2021) examine the alleles and phenotypes in dachshunds and identified cryptic, hidden, and mosaic variants that had no merle phenotype. The variation in PMEL is an extreme example of allelic heterogeneity and variable expressivity, and demonstrates the critical need for laboratory testing, so that breeders can make informed decisions and avoid producing dogs with two copies of certain $P M E L$ variants that can lead to eye anomalies and deafness.

\section{Novel findings identified for inherited diseases in dogs}

Certain dog breeds have been identified with familial, nonsyndromic mitral valve disease. In this issue, Williams et al. (2021) used 50 dogs from 5 breeds that had been phenotyped for disease. Using genome sequencing, variants were identified and evaluated for pathogenicity. Although no shared variants were found in the $50 \mathrm{dogs}$ studied, the authors did identify a small number of intergenic and intronic variants that were located around and within $M E D 13 L$, but their impact on disease will require further study.

Two point mutations in SODI are known to cause degenerative myelopathy in a variety of dog breeds (Zeng et al. 2014) and are animal models for amyotrophic lateral sclerosis in humans. In this issue, Mandigers et al. (2021) identified a frameshift mutation in the Dutch Markiesje dog breed that leads to an autosomal recessive form of juvenile paroxysmal dyskinesia. This research provides an animal model for a juvenile, progressive spastic tetraplegia, and axial hypotonia (OMIM 618598).

We were very fortunate to have received several submissions from the prolific canine research laboratory of Hannes Lohi (Niskanen et al. 2021; Kyöstilä et al. 2021; Kaukonen et al. 2021; Hytönen et al. 2021a,b). In the first paper, Niskanen et al. (2021) investigated the known variant in $D V L 2$ associated with kinked tails and brachycephaly in bulldog breeds in an additional 1954 dogs from 15 breeds. The researchers confirmed that this deletion variant is associated with caudal vertebral malformations and brachycephaly, and may be involved with brachycephalic obstructive airways and congenital heart defects.

A genetic cause of canine pituitary dwarfism was previously known for German shepherd dogs. In this special issue, Kyöstilä et al. (2021) identified a novel homozygous variant in the POU1F1 gene in affected Karelian Bear dogs. After screening more than 8000 dogs from 207 breeds, only a related breed, Lapponian Herder, was found to also carry this mutation at a low frequency.

As a class of disorders, canine progressive retinal atrophies (PRA) are some of the more common mutations identified in the domestic dog and provide animal models for many types of retinitis pigmentosa in humans (Bunel et al. 2019). Although many mutations are known, the Lapponian Herder can have a PRA not explained by these known variants. In this special issue, Kaukonen et al. (2021) identify a homozygous missense mutation in the IFT122 gene that may explain the genetic basis for some of the PRA in this breed.

Nonsyndromic hearing loss is a significant medical problem in many breeds of dogs, yet the genetic bases have remained elusive. In this issue of Human Genetics, Hytönen et al. (2021a) identify a missense variant in LOXHD1 in the Rottweiler dog, a gene that is known to be essential for cochlear hair cell function. This gene contributes to hearing loss in humans and mice, and represents the first identified variant for nonsyndromic hearing loss in dogs.

A neurodegenerative disorder in the Parson Russel Terrier was investigated by Hytönen et al. (2021b). Affected dogs develop normally until about 6-12 weeks of life before the onset of severe seizures that can progress to status epilepticus and death. A 6-base pair homozygous deletion in PITRM1 was identified as the probable underlying cause of this disease and provides a canine model for neurodegenerative disease with mitochondrial respiratory deficiency and severe epileptic encephalopathy.

\section{Copy-number variation in dogs}

The last paper in this issue uses microarray technologies to identify copy-number variation and the identification of the first autosomal aneuploidy in dogs (Shaffer et al. 2021b). 
This publication is rather special to me as it is the culmination of a 30-year career in genetics. Coming full circle in my career, my first cytogenetics publication was in 1991 in Human Genetics on isochromosomes of chromosome 21 resulting in Down syndrome (Shaffer et al. 1991). My first company, Signature Genomics Laboratories, was the first laboratory to transition from traditional cytogenetics to microarray-based approaches for the detection of segmental aneusomies and aneuploidies and published the first large study of the use of microarrays in clinical testing (Shaffer et al. 2006). To be the first to publish cytogenetic anomalies detected by microarray analysis in dogs seems a fitting way to end a 30-year career dedicated to developing new technologies for chromosome analysis and the identification of new syndromes and the genes that contribute to their phenotypes.

In summary, this special issue of Human Genetics dedicated to companion animal genetics includes papers that demonstrate the use of genome-wide technologies and targeted approaches in identifying novel variants in cats and dogs. In addition to some discoveries providing animal models for human diseases, most can be developed into clinical tests that can aid breeders and veterinarians in improving the health of these animals. I hope that you enjoy reading this special issue as much as I enjoyed working with the talented researchers represented in this body of work, as it was truly a labor of love.

\section{References}

Ballif BC, Ramirez CJ, Carl CC, Sundin K, Krug M, Zahand A, Shaffer LG, Flores-Smith H (2018) The PMEL gene and merle in the domestic dog: A continuum of insertion lengths leads to a spectrum of coat color variations in Australian shepherds and related breeds. Cytogenet Genome Res 156:22-34

Ballif BC, Emerson LJ, Ramirez CJ, Carl CC, Sundin KS, Flores-Smith $\mathrm{H}$, Shaffer LG (2021) The PMEL gene and merle (dapple) in the dachshund: cryptic, hidden, and mosaic variants demonstrate the need for genetic testing prior to breeding. Hum Genet. https://doi. org/10.1007/s00439-021-02330-y

Bunel M, Chaudieu G, Hamel C, Lagoutte L, Manes G, Botherel N, Brabet P, Pilorge P, André C, Quignon P (2019) Natural models for retinitis pigmentosa: progressive retinal atrophy in dogs breeds. Hum Genet 138:441-453

Hytönen MK, Niskanen JE, Arumilli M, Brookhart-Knox CA, Donner J, Lohi H (2021a) Missense variant in LOXHD1 is associated with canine nonsyndromic hearing loss. Hum Genet. https://doi.org/10. 1007/s00439-021-02286-z

Hytönen MK, Sarviaho R, Jackson CB, Syrjä P, Jokinen T, Matiasek K, Rosati M, Dallabona C et al (2021b) In-frame deletion in canine PITRM1 is associated with a severe early-onset epilepsy, mitochondrial dysfunction and neurodegeneration. Hum Genet. https:// doi.org/10.1007/s00439-021-02279-y

Kaukonen M, Pettinen I-T, Wickström K, Arumilli M, Donner J, Juhola I-J, Holopainen S, Turunen JA, Yoshihara M, Kere J, Lohi
H (2021) A missense variant in IFT122 associated with a canine model of retinitis pigmentosa. Hum Genet. https://doi.org/10. 1007/s00439-021-02266-3

Kyöstilä K, Niskanen JE, Arumilli M, Donner J, Hytönen MK, Lohi H (2021) Intronic variant in POU1F1 associated with canine pituitary dwarfism. Hum Genet. https://doi.org/10.1007/ s00439-021-02259-2

Mandigers PJJ, Van Steenbeek FG, Bergmann W Vos-Loohuis M, Leegwater PA (2021) A knockout mutation associated with juvenile paroxysmal dyskinesia in Markiesje dogs indicates SOD1 pleiotropy. Hum Genet. https://doi.org/10.1007/ s00439-021-02271-6

Niskanen JE, Reunanen V, Salonen M, Bannasch D, Lappalainen AK, Lohi H, Hytönen MK (2021) Canine DVL2 variant contributes to brachycephalic phenotype and caudal vertebral anomalies. Hum Genet. https://doi.org/10.1007/s00439-021-02261-8

Online Mendelian Inheritance in Animals (2021) https://omia.org/ home/. Accessed 15 Sep 2021

Orthopedic Foundation for Animals (2021) https://www.ofa.org/disea ses/dna-tested-diseases/all-dna-tests. Accessed 15 Sep 2021

Rokhsar JL, Canino J, Raj K, Yuhnke S, Slutsky J, Giger U (2021) Web resource on available DNA variant tests for hereditary diseases and genetic predispositions in dogs and cats: an update. Hum Genet. https://doi.org/10.1007/s00439-021-02256-5

Rorden C, Griswold MC, Moses N, Berry CR, Keller GG, Rivas R, Flores-Smith H, Shaffer LG, Malik R (2021) Radiographical survey of osteochondrodysplasia in scottish fold cats caused by the TRPV4 gene variant. Hum Genet. https://doi.org/10.1007/ s00439-021-02337-5

Shaffer LG (2019) Special issue on canine genetics: animal models for human disease and gene therapies, new discoveries for canine inherited diseases, and standards and guidelines for clinical genetic testing for domestic dogs. Hum Genet 138:437-440

Shaffer LG, Jackson-Cook CK, Meyer JM, Brown JA, Spence JE (1991) A molecular genetic approach to the identification of isochromosomes of chromosome 21. Hum Genet 86:375-382

Shaffer LG, Kashork CD, Saleki R, Rorem E, Sundin K, Ballif BC, Bejjani BA (2006) Targeted genomic microarray analysis for identification of chromosome abnormalities in 1500 consecutive clinical cases. J Peds 149:98-102

Shaffer GD, Ballif BC, Meurs K, Shaffer LG, Flores-Smith H (2021a) Identification of a novel missense mutation in the fibroblast growth factor 5 gene associated with longhair in the Maine coon cat. Hum Genet. https://doi.org/10.21203/rs.3.rs-575619/v1

Shaffer LG, Hopp B, Switonski M, Zahand A, Ballif BC (2021b) Identification of aneuploidy in dogs screened by a SNP microarray. Hum Genet. https://doi.org/10.1007/s00439-021-02318-8

Williams B, Friedenberg SG, Keene BW, Tou SP, DeFrancesco TC, Meurs KM (2021) Use of whole genome analysis to identify shared genomic variants across breeds in canine mitral valve disease. Hum Genet. https://doi.org/10.1007/s00439-021-02297-w

Zeng R, Coates JR, Johnson GC, Hansen L, Awano T, Kolicheski A, Ivansson $\mathrm{E}$ et al (2014) Breed distribution of SOD1 alleles previously associated with canine degenerative myelopathy. J Vet Intern Med 28:515-521

Publisher's Note Springer Nature remains neutral with regard to jurisdictional claims in published maps and institutional affiliations. 